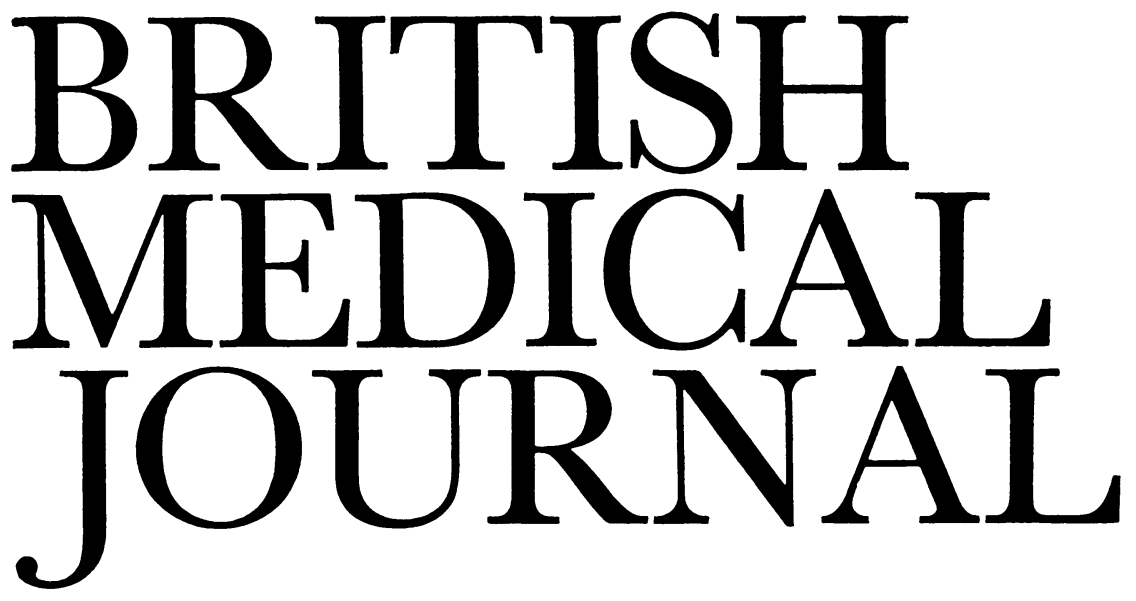

LONDON, SATURDAY 25 JULY 1981

\title{
Audit in renal failure: the wrong target?
}

For nearly two decades the British public has been told that patients with renal failure are dying because of inadequate facilities, and recent reviews ${ }^{12}$ have presented convincing data in support of this claim. Some Americans believe that rationing of these facilities is accepted government policy in Britain, ${ }^{3}$ though no such policy has been accepted publicly by any British government. ${ }^{2}$ The provision of treatment is limited by restricting the supply of funds to the relevant parts of the Health Service and by other subtle restraining influences imposed by the NHS bureaucracy. ${ }^{2}$

This week ( $p$ 283) we are publishing a report prepared by Sir Cyril Clarke and Professor A G Whitfield for the Royal College of Physicians which claims that patients in Britain who die from renal failure do so not because of lack of facilities but either because they are not suitable for treatment or because treatment fails. We believe that in part these conclusions are wrong and may mislead. With the agreement of the authors, we are taking the unusual step of publishing a paper criticised by our referees together with a leading article setting out those criticisms at length. Our two reasons are, firstly, the importance of the topic-is renal failure undertreated in Britain ?-and, secondly, the need for close public examination of the profession's efforts at self-audit. We must emphasise that our criticisms are made not to condemn an admirable project, several of whose papers we have published, or two distinguished physicians but as an attempt to balance difficult issues.

The report of the Study Group of the Royal College of Physicians was sent out for review in our usual way. The opinions drew attention to the lack of reference to all the available data, to a probable shortfall in ascertainment, and to the essentially anecdotal nature of the report. One reviewer commented that the conclusions would mislead the public into thinking there was not a problem, and that the report read as a defensive statement. Nevertheless, the $B M \mathcal{F}$ considers, a report as provoking as this should not be suppressed but its conclusions must not be accepted without considering the validity of the data on which they are based.

The study group considered only those patients below the age of 50 dying in hospital of renal failure. This was the wrong target. The main concern among renal physicians in Britain is that very few patients aged over 50 enter the treatment programmes, though the results of providing dialysis and transplantation can be satisfactory in such patients. ${ }^{4}$ Careful epidemiological surveys ${ }^{5-7}$ based on the evaluation of all patients with raised plasma urea values have shown that around 15 to 20 new patients aged between 50 and 65 should present from each million population each year. Indeed, treatment may be successful in patients older than 65 . The same surveys have estimated that there should be around 30 patients under 50 years needing treatment for each million population. In the regions surveyed by the Royal College of Physicians data on patients of all ages show that around 17 patients per million population were accepted for treatment in 1979. The average for the whole of the United Kingdom is 22 per million, with a maximum of 40 per million ${ }^{8}$ in one metropolitan region (in which there are difficulties in knowing the population from which the patients are drawn). Some other regions accept 30 per million per year. The treatment rate in the regions considered by Clarke and Whitfield is, therefore, less than half of that reached elsewhere in Britain.

The Royal College of Physicians report found that patients with renal failure, and under 50 , received dialysis or transplantation when they were considered "suitable" and were seen by the physicians in charge of the facilities that provide these treatments. It lists 53 patients in whom there were "reasons for not offering dialysis" and who were classified as "unsuitable." This distinction must be made correctly if the conclusions are to be accepted as valid. The report does not make clear who made this evaluation, either when patients were initially classified as "unsuitable" or when the retrospective analysis was made and the conclusions accepted. Who did the audit? The physicians who advised on the preparation of the report were experts in the specialty and themselves had looked after many of the patients studied-and came from regions which have among the lowest treatment rates per million in Britain. Were the notes reviewed by one or more "independent" and expert physicians? Were they critically reviewed with the thought in mind that a doctor deciding that treatment is inappropriate or unavailable may write his notes to support that view? Dissenting thoughts or opinions are unlikely to be committed to paper. Probably very few of the patients included in the study would have given rise to serious doubts about "suitability"-but a study of this sort must examine those few cases in considerable detail if it is to carry 
conviction. Renal physicians working in countries and regions with increasing facilities find more and more patients "suitable" as resources increase, ${ }^{9}$ showing the subjective nature of the decision making. ${ }^{10}$

A second group of patients identified in this study who would merit more detailed critical analysis were those dying during evaluation and during the first weeks on dialysis. Were these patients referred to specialist centres too late ? Earlier diagnosis or referral, and an earlier entry to the dialysis programme, might have lowered mortality. More units, with better funding, would help reduce this mortality. Several surveys have shown a correlation between the number of units, the acceptance rate of patients on to renal replacement programmes, and the total number of patients having treatment. ${ }^{411}$ More units also means more renal physicians, who may then make decisions earlier and under less pressure. The time available to assess suitability for this lifesaving treatment is often limited (and makes an interesting contrast with the time judges demand for decisions of rather less importance).

The study group has shown up another defect in current practice with its finding ( $p$ 286) that kidneys were obtained for transplantation from only 20 of 1168 patients under 50 dying from medical causes. Doctors should, the report suggests, do more to overcome their reluctance to approach relatives for consent to organ donation.

Doctors need medical audit in some form to ascertain, among other things, whether they treat too few patients or too many. Life with treatment for some patients with renal failure may only be a prolongation of the process of dying. In the United States $20 \%$ of the patients having dialysis were considered in a recent and preliminary report ${ }^{12}$ to be severely debilitated and requiring some aid even just for bodily needs, and such treatment must be inappropriate for some of these. The proportion of debilitated patients is much lower in Britain ${ }^{8}$ but is likely to rise if more patients are accepted on to treatment programmes. A recent leading article in the New England Fournal of Medicine has contrasted favourably the progress made in Europe in monitoring the clinical activities of nephrologists with similar efforts in the United States. ${ }^{13}$ More work is needed on this problem; some of the conclusions in the reports of the European Dialysis and Transplant Association and the UK Transplant Service might not be substantiated if there was a more rigorous statistical evaluation. ${ }^{14}$ The Royal College of Physicians report makes little reference to the many earlier publications or to their strengths and weaknesses. It is itself perhaps best regarded as an experience of another method of collecting data and of evaluating evidence-a method that needs to be much more thorough if the conclusions reached are to be considered important as they could be with improved methods.

As Mitchell has recently said in another context, ${ }^{15}$ years of hard slog may serve merely to expose the trialists to a barrage of criticism and questions. Nevertheless, much as we admire the study group's intentions, its investigation lacked some essential features-epidemiological, statistical, and clinical. A study of case notes cannot produce good data when the notes themselves are so often inadequate. What is needed is a prospective study with a tightly controlled protocol. Retrospective benign audit of this kind may have unintended but far-reaching consequences. Governments may be encouraged to believe that they have succeeded when they have not, and doctors may think they are not making errors when they still have much to learn.

${ }^{1}$ Laing W. OHE briefing. End stage renal failure. London: Office of Health Economics, 1980.
${ }^{2}$ Knapp MS. The organisation of dialysis services and the role of transplantation. Int $\mathcal{F}$ Artif Organs 1979;2:269-72.

${ }^{3}$ Held PJ, Pauly MV, Smits HL. Treatment of end-stage renal disease. N Engl f Med $1981 ; 304: 355$.

${ }^{4}$ Brunner FP, Brynger $\mathrm{H}$, Chantler $\mathrm{C}$, et al. Combined report on regular dialysis and transplantation in Europe, X, 1979. Proc Eur Dial Transplant Assoc 1980;17:4-86.

${ }^{5}$ Branch RA, Clark GW, Cochrane AL, Jones JH, Scarborough $\mathrm{H}$. Incidence of uraemia and requirements for maintenance haemodialysis. Br Med f 1971;i:249-54.

${ }^{6}$ Pendreigh DM, Heasman MA, Howitt LF, et al. Survey of chronic renal failure in Scotland. Lancet 1972; i :304-7.

${ }^{7}$ Dombey SL, Sagar D, Knapp MS. Chronic renal failure in Nottingham and requirements for dialysis and transplant facilities. $\mathrm{Br} \mathrm{Med} \mathcal{f}$ $1975 ; \mathrm{ii}: 484-5$.

${ }^{8}$ UK Transplant Service. Annual report 1980. Bristol: UK Transplant Service, 1981.

${ }^{9}$ Relman AS, Rennie D. Treatment of end-stage renal disease: free but not equal. $N$ Engl f Med $1980 ; 303: 996-8$.

10 Taylor TR, Aitchison J, Parker LS, Moore MF. Individual differences in selecting patients for regular haemodialysis. Br Med f 1975 ;ii:380-1.

${ }^{11}$ Executive Committee of the Renal Association. Distribution of nephrological services for adults in Great Britain. Br Med f 1976;ii:903-6.

12 Gutman RA, Stead WW, Robinson RR. Physical activity and employment status of patients on maintenance dialysis. N Engl f Med 1981;304: 309-13.

${ }^{13}$ Rennie D. Renal rehabilitation-where are the data? $N$ Engl $f$ Med $1981 ; 304: 351-2$.

${ }^{11}$ Knapp MS. Evaluating the treatment of renal failure by dialysis and transplantation. Lancet 1977 ;i : 1068-9.

${ }^{15}$ Mitchell JRA. Timolol after myocardial infarction: an answer or a new set of questions? Br Med f 1981;282:1565-70.

\section{Haematology in developing countries}

Anaemia is a major world health problem; its prevalence in different regions needs to be known both for planning public health programmes and for the management of patients. Measurement of the haemoglobin concentration is the essential laboratory test for both aspects; what other tests should and can be performed in elucidating the cause of anaemia in an individual patient will vary with the main types of anaemia found in a region and on the facilities available to the investigator. The World Health Organisation has a primary duty to advise on needs of health care in developing countriesincluding provision of appropriate and adequate laboratory facilities to help solve the problem of anaemia.

Several levels of health service must be catered for. These range from primary (predominantly rural) care with one health worker and no organised laboratory facilities to regional or national institutes capable of performing the most complex tests. Between these extremes there are three intermediate levels with laboratory facilities of varying extent. The first, the district hospital, will usually have a trained technician capable of performing a comprehensive range of laboratory tests; secondly, the primary level hospital should have at least an assistant who has been trained to perform a limited number of diagnostic tests; while, thirdly, in the health centre or dispensary there should be a laboratory aide with some technical training. Over the years the World Health Organisation has given much thought to the questions of who to recruit for these various tasks, how they should be trained, and how they should be equipped. ${ }^{1-3}$

The International Committee for Standardisation in Haematology is concerned with promoting reliability and accuracy in haematology laboratory analysis. Until recently the committee concentrated mainly on developing reference methods, but such advanced technology is not incompatible with the development of simple laboratory tests; indeed, the 